\title{
A new species of Mesocoelium (Digenea: Mesocoeliidae) found in Rhinella marina (Amphibia: Bufonidae) from Brazilian Amazonia
}

\author{
Tássia FF Gomes', Francisco TV Melo', Elane G Giese², \\ Adriano P Furtado', Evonnildo C Gonçalves ${ }^{3}$, Jeannie N Santos ${ }^{1 /+}$
}

\footnotetext{
'Laboratório de Biologia Celular e Helmintologia Profa Dra Reinalda Marisa Lanfredi ${ }^{3}$ Laboratório de Tecnologia Biomolecular, Instituto de Ciências Biológicas, Universidade Federal do Pará, Belém, PA, Brasil 'Laboratório de Histologia e Embriologia Animal, Instituto de Saúde e Produção Animal, Universidade Federal Rural da Amazônia, Manaus, AM, Brasil
}

Mesocoelium lanfrediae sp. nov. (Digenea: Mesocoeliidae) inhabits the small intestine of Rhinella marina (Amphibia: Bufonidae) and is described here, with illustrations provided by light, scanning electron microscopy and molecular approachs. M. lanfrediae sp. nov. presents the typical characteristics of the genus, but is morphometrically and morphologically different from the species described previously. The main diagnostic characteristics of M. lanfrediae $s p$. nov. are (i) seven pairs of regularly-distributed spherical papillae on the oral sucker, (ii) ventral sucker outlined by four pairs of papillae distributed in a uniform pattern and interspersed with numerous spines, which are larger at the posterior margin and (iii) small, rounded tegumentary papillae around the opening of the oral sucker, which are morphologically different from those of the oral sucker itself, some of which are randomly disposed in the ventrolateral tegumentary region of the anterior third of the body. Addionally, based on SSU rDNA, a phylogenetic analysis including Brachycoeliidae and Mesocoeliidae taxa available on GenBank established the close relationship between M. lanfrediae sp. nov. and Mesocoelium $s p$.

Key words: Trematoda - cane toad - Mesocoelium - molecular phylogeny

The natural range of the cane toad, Rhinella marina (Linnaeus, 1758) (syn. Bufo marinus and Chaunus marinus) stretches from southern Texas to central Brazil. However, the species has also been introduced into a number of regions, such as Florida, Caribbean and $\mathrm{Pa}-$ cific islands, New Guinea and northwestern Australia, for the biological control of agricultural pests (Barton 1997, Ragoo \& Omah-Maharaj 2003, Espinoza-Jiménez et al. 2007, Vallinoto et al. 2010).

The family Mesocoeliidae Dollfus, 1929 (Digenea) is composed by parasites of the digestive organs of a number of amphibian and reptile species including $R$. marina This family has two genera: Mesocoelium Odhner, 1910 and Pintneria Poche, 1907 (Pojmanska 2008). This paper describes the morphological and molecular characteristics of a parasite of the genus Mesocoelium, which appear to be unique and have thus led us to propose a new species.

\section{MATERIALS AND METHODS}

Fourteen cane toads (R. marina) were collected within the urban area of the Belém, capital of the Brazilian state of Pará (PA), eastern Amazonia. The animals were anesthetized with sodium tiopenthal, weighed and euthanized by exsanguinations [Animal Research Ethical Committee of the Federal University of Pará (CEPAEUFPA) license BIO 010-10].

Financial support: CAPES-PROCAD/2005, CAPES-PROCAD NF/2009, PROPESP/FADESP-UFPA, CNPq-SISBiota/2010

+ Corresponding author: jeannie@ufpa.br

Received 7 February 2012

Accepted 15 May 2012
The digestive tube of each toad was isolated in phosphate buffered solution $\mathrm{pH} 7.4$ and analyzed for trematodes. For light microscopy analysis, 10 parasites were fixed with $2 \%$ glacial acetic acid, $3 \%$ formaldehyde, $95 \%$ ethanol $70^{\circ}$, dehydrated in increasing ethanol concentrations, stained in alcoholic chloridric carmine, bleached in methyl salicylate and mounted in Entellan ${ }^{\mathrm{TM}}$. Illustrations were drawn with camera lucida attached to an Olympus BX41 microscope. Measurements are presented in millimetres, unless otherwise indicated, as means and standard deviations, with the range of values in parentheses.

For scanning electron microscopy (SEM), 20 specimens were fixed with $2.5 \%$ glutaraldehyde, post-fixed in $1 \% \mathrm{OsO}_{4} 0.8 \% \mathrm{~K}_{2} \mathrm{Fe}(\mathrm{CN})_{6}$, gold sputtered and observed in a Jeol JSM-5310 scanning electron microscope.

Molecular characterization of three parasites was based on complete SSU rDNA gene, which after DNA extraction through the ChargeSwitch gDNA Mini Tissue Kit (Invitrogen Life Technologies), was amplified in two overlapping fragments using the primers $18 \mathrm{~S}$ E/18S-A27 and 18S-8/cestode- 6 according to Olson and Caira (1999). The polymerase chain reactions (PCRs) were carried out in $25 \mu \mathrm{L}$ final volume, containing 5-10 ng of DNA, $50 \mathrm{mM} \mathrm{KCl}, 2 \mathrm{mM} \mathrm{MgCl}, 10 \mathrm{mM}$ Tris-HCl, $50 \mu \mathrm{M}$ of each DNTP, $0.5 \mu \mathrm{M}$ of each oligonucleotide and one unit of Taq DNA polymerase (Invitrogen). Reactions using the 18S-E/18S-A27 primers were denatured for $5 \mathrm{~min}$ at $95^{\circ} \mathrm{C}$ followed by 35 cycles, $1 \mathrm{~min}$ thermal denaturing cycles at $94^{\circ} \mathrm{C}, 1 \mathrm{~min}$ at $68^{\circ} \mathrm{C}$ for annealing and 1 min extension at $72^{\circ} \mathrm{C}$, with a final 7 min extension at $72^{\circ} \mathrm{C}$. Reactions using the $18 \mathrm{~S}-8 /$ cestode- 6 primers were amplified following the same procedure, except for annealing temperature of $64^{\circ} \mathrm{C}$. Amplicons were electrophoresed in a $1 \%$ agarose gel, excised and puri- 
fied with GFX PCR DNA and Gel Purification Kit (GE Healthcare). An aliquot of each purified product was ligated into pGEM-T Vector (Promega) overnight and then desalted before electroporation into Escherichia coli TOP 10 (Invitrogen Life Technologies). Inserted DNA of whites clones were obtained by PCR directly from colonies using M13F/M13R primers and sequenced automatically in a 3130 Genetic Analyzer (Applied Biosystems), according to the maker's specifications. Both forward and reverse primers were used for sequencing reactions to confirm sequences. BioEdit software (Hall 2007) was used to align sequences.

Phylogenetic relationship of new species of $\mathrm{Me}$ socoelium was made between the only data available GenBank on families Brachycoeliidae Looss, 1899 and Mesocoeliidae taxa, including Brachycoelium salamandrae Frölich, 1789 (GenBank accession AY222160) and Mesocoelium sp. (GenBank accession AJ287536), was performed through Bayesian inference using Markov Chain Monte Carlo (MCMC) tree searches using MrBayes 3.1.2 (Ronquist \& Huelsenbeck 2003). Based on Hasegawa-Kishino-Yano model, proportion of invariable sites and gamma model of DNA substitution with the empirical base frequencies $(\mathrm{A}=0.2337, \mathrm{C}=0.2223$, $\mathrm{G}=0.2814, \mathrm{~T}=0.2626), \mathrm{ti} / \mathrm{tv}$ ratio $=2.5121$, proportion of invariable sites $=0.3374$ and gamma distribution shape parameter $=0.2383$, which was selected as the most appropriate model of evolution by Modeltest 3.06 (Posada 2008), under the Bayesian Information Criterion (Schwarz 1978), we performed two parallel runs of four simultaneous MCMC searches for 5 million generations each, sampling one tree every 500 generations and discarding results of the first 1,000 trees as "burn-in". The remaining trees were used by MrBayes to estimate the posterior probability of each node in our phylogenetic reconstruction. Tracer v1.4.1 was used to check the stationarity of all parameters sampled by the chains (Rambaut \& Drummond 2008). According Olson et al. (2003) we used Rubenstrema exasperatum (GenBank accession AJ287572) as outgroup.

Ethics - The present study was approved by CEPAEUFPA through authorization BIO010-10.

\section{RESULTS}

The small intestine of nine (64.3\%) of the 14 specimens was completely parasited with mesocoeliid trematodes.

\section{Mesocoelium lanfrediae sp. nov.}

(Figs 1-18)

Diagnosis (based on the holotype and 9 paratypes) Mesocoeliidae. Body elongate, $2.453 \pm 0.508$ (1.37-3.00) $\times 1.01 \pm 0.13(0.79-1.23)$ at the testis level. Extremities rounded. Tegument spinose up to midbody. Oral sucker subterminal, ventrally directed, $0.232 \pm 0.028(0.17-0.27)$ $\times 0.237 \pm 0.017(0.22-0.28)$, oral aperture anteroventral. Ventral sucker round, pre-equatorial, $0.206 \pm 0.020(0.16$ $0.24) \times 0.205 \pm 0.024(0.15-0.23)$. Sucker width ratio 1:1 Prepharynx not observed. Pharynx large, strongly muscular, $0.105 \pm 0.020(0.07-0.13) \times 0.094 \pm 0.015(0.06-$ 0.11). Esophagus short. Intestinal ceca short, extending posteriorly beyond ventral sucker; right cecum $0.981 \pm$
0.24 (0.52-1.24), left cecum $0.969 \pm 0.24$ (0.45-1.3). Testis intercecal, round, oblique, post ventral sucker; right testes $0.220 \pm 0.07(0.12-0.35) \times 0.229 \pm 0.069(0.13-$ 0.33 ), left testes $0.229 \pm 0.069(0.13-0.33) \times 0.223 \pm 0.062$ (0.13-0.34). Cirrus sac before to ventral sucker, $0.19 \pm$ $0.038(0.13-0.25) \times 0.075 \pm 0.023(0.04-0.11)$. Seminal vesicle located below the prostate gland, not bipartite. Small prostatic glands. Genital pore at the level of the intestinal bifurcation. Ovary round, below right testes, $0.172 \pm 0.042(0.12-0.25) \times 0.18 \pm 0.039(0.11-0.23)$. Seminal receptacle and Mehlis'gland present, but difficult to observe. Oral sucker with seven pairs of small spherical papillae. Three pairs together close to the anterior extremity and four other pairs widely, regularly-spaced around the oral sucker. Vitelline glands lateral, extending from pharynx to cecal extremity. Uterus extensive, highly convoluted, with descending and ascending limbs overlapping ceca. Metraterm on left side of body close to the genital pore. Eggs operculate, $0.032 \pm 0.001(0.03$ $0.034) \times 0.023 \pm 0.002(0.002-0.028)$. Excretory vesicle Y-shaped, short. Terminal excretory pore.

Description of M. lanfrediae sp. nov. by SEM - The intestinal mucosa of $R$. marina present large numbers of trematodes attached to the surface with different levels of adhesion. Some parasites were covered by a mucous layer, while others were totally inserted within the intestinal villi by the oral sucker and the ventral sucker (Figs 6,7). Details of the ventral surface of the parasite confirm the subterminal position oral sucker, the genital pore opening near to the ventral sucker and the terminal excretory pore (Figs 8,9 ). The oral sucker opening with a small lump at the anterior extremity formed by an elevation of the tegument. Seven pairs of small spherical papillae in the oral sucker, distributed in a $3+1+1+1$ +1 formation, with three pairs together close to the anterior extremity of the opening and four other pairs more widely are observed (Fig. 10). Small, rounded papillae are found in the tegumentary region around the opening of the oral sucker, with large central structures and an irregular contour (Figs 14, 15). These tegumentary papillae are different sizes from those of the oral sucker and some are randomly disposed in ventrolateral region on the first third of the body. The tegument is covered with delicate cuneiform spines and is arranged from anterior region to the beginning of posterior third of the body, being more visible on the ventrolateral surface of the mid portion of the body (Figs 9, 16, 17). The genital pore with raised contour without papillae is located between the oral sucker and the ventral sucker, presenting an unarmed cirrus in which spermatozoids can be seen (Fig. 11). The ventral sucker outlined by four pairs of papillae distributed around the perimeter of the opening, the papillae are interspersed with numerous spines, which are larger at the posterior margin of the organ (Fig. 12). Oral sucker and ventral sucker were fixed in different contraction levels (Figs 8,9). The excretory pore with a spherical opening with pleats, but no spines or papillae (Figs 8,13 ). The elliptical eggs have a slightly grainy surface and a small elevation outlining the perimeter of the operculum (Fig. 18). 
Type host - R. marina (Linnaeus, 1758) (syn. B. marinus, C. marinus) (Anura: Bufonidae).

Site of infection - Small intestine.

Type locality - Belém, PA, Brazil (01²8"03"S $48^{\circ} 20^{\prime \prime} 18^{\prime \prime} \mathrm{W}$ ).

Type data and depository - The holotype and nine paratypes deposited in the Collection of the Platyhelminthes of Museu Paraense Emilio Goeldi (deposit 20120400001).

Host-parasite data - Prevalence: $64.28 \%$.

Molecular evidences - The complete sequence of SSU rDNA contain 1,981 bp and was submitted to GenBank with accession JQ886404. The uncorrected sequence di- vergence between Brachycoeliidae and Mesocoeliidae taxa ranged from $1 \%$ (M. lanfrediae sp. nov. vs. Mesocoelium sp.) to $2.1 \%$ (M. lanfrediae sp. nov. vs. B. salamandrae), whereas for comparison involving the outgroup ( $R$. exasperatum), values were $2.7 \%, 3 \%$ and $3.1 \%$, respectively, related to M. lanfrediae sp. nov., B. salamandrae and Mesocoelium sp. According our phylogenetic analysis, the close relationship between $M$. lanfrediae sp. nov. and $\mathrm{Me}$ socoelium $\mathrm{sp}$. was established conclusively (Fig. 19).

Remarks - The descriptions of Cheng (1960), Freitas (1963) and Nasir and Díaz (1971) should be considered to classify a species in genus Mesocoelium. Then, M. lanfrediae sp. nov. did not have morphological characters to belong to the 28 species previously classified by Cheng (1960) and did not to the actually accepted seven spe-
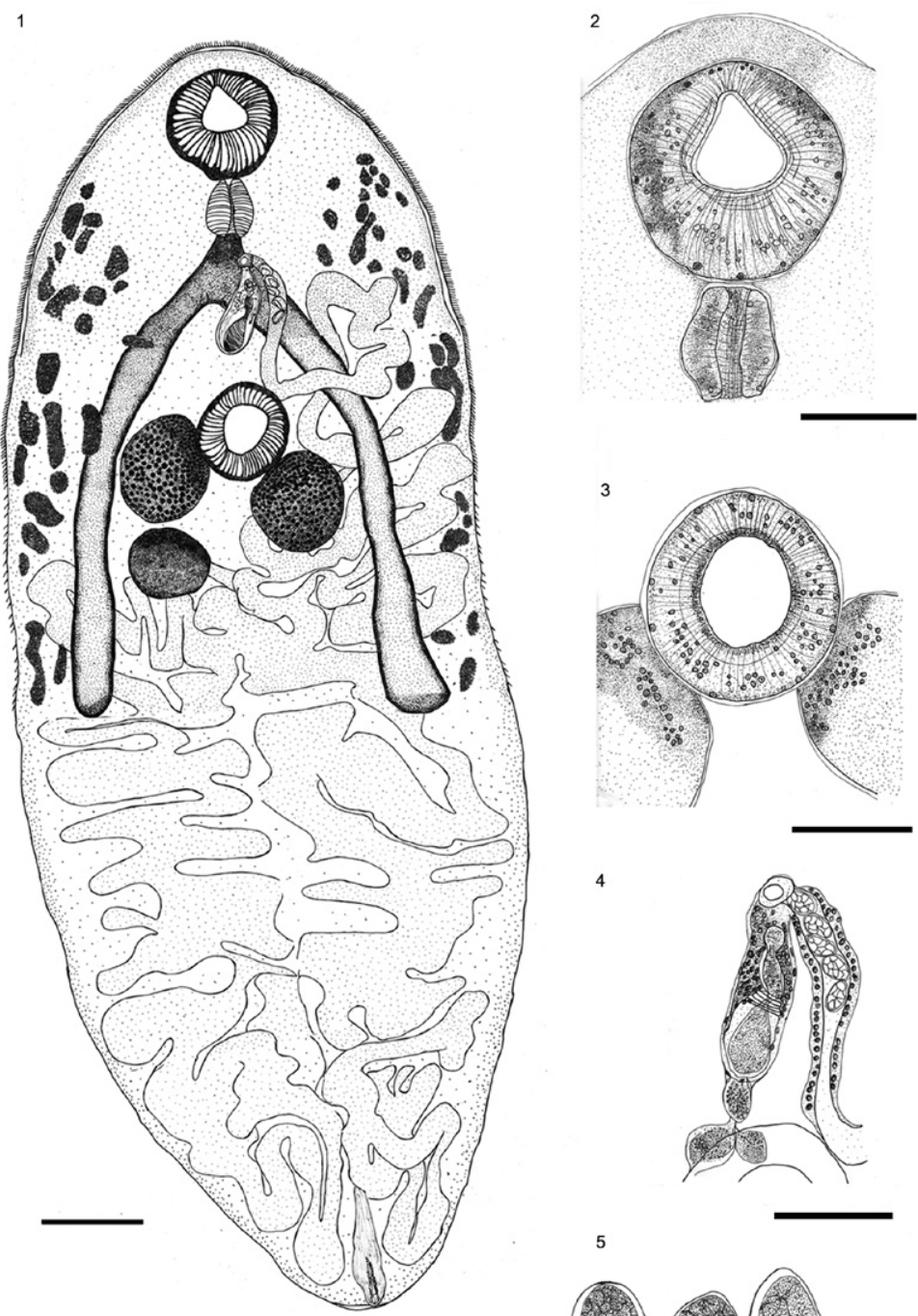

4

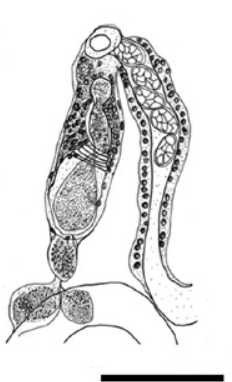

5

Figs 1-5: line drawings obtained from light microscopy of Mesocoelium lanfrediae sp. nov. 1: general view of whole worm $($ Bar $=200$ um); 2 3: details of the oral sucker and acetabulum, showing the subtile view and distribution of the papillae (Bar $=100 \mu \mathrm{m})$; 4 : detail of genital pore aperture and cirrus sac $(\mathrm{Bar}=100 \mu \mathrm{m}) ; 5$ : details of the eggs found in large quantities in the uterus of the helminth $(\mathrm{Bar}=50 \mu \mathrm{m})$. 
cies for the genus. The morphometry of the new species is larger in total length, width, pharynx lenght, cirrus pouch, testis, ovary, egg diameter. Some morphological aspects as the oblique testis and the presence of oral and ventral sucker papillae distributed in a precise pattern are inherent of the new species.

\section{DISCUSSION}

The taxonomy of the genus Mesocoelium is complex and has been the subject of considerable controversy since the 1960's (Cheng 1960, Nasir \& Díaz 1971). In the most recent identification key for the Trematoda, Pojmanska (2008) adopted the arrangement of Dollfus (1933), in which Mesocoelium belongs to the family Mesocoelii-
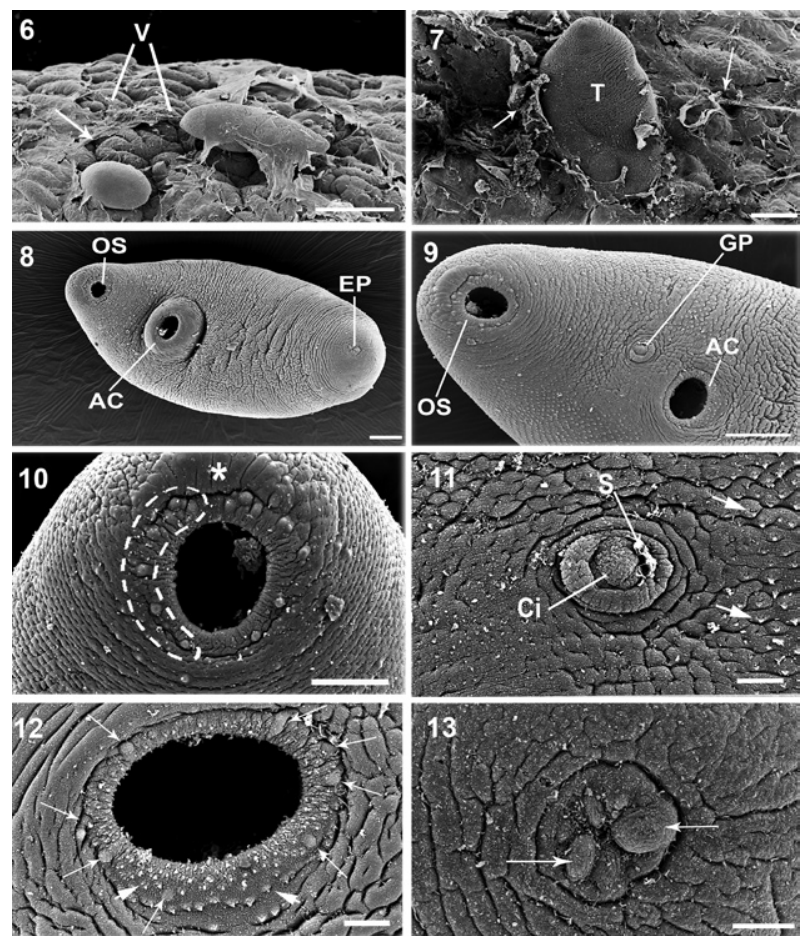

Figs 6-13: scanning electron micrographs of Mesocoelium lanfrediae sp. nov. 6-7: dorsal view of the trematode (T) showing different levels of adherence to the surface of the intestinal cells (V) and the mucous covering (arrows) (Bar $=500 \mu \mathrm{m}$ and $200 \mu \mathrm{m}$, respectively); 8: general view of trematode ventral surface, showing the oral sucker (OS), protruding acetabulum (AC) and excretory pore (EP) $(\mathrm{Bar}=100$ $\mu \mathrm{m})$; 9: general view of the ventral surface of the anterior and midthird of a relaxed trematode, showing the aperture of the OS, genital pore $(\mathrm{GP})$ and uncontracted $\mathrm{AC}(\mathrm{Bar}=100 \mu \mathrm{m}) ; 10$ : details of the oral sucker showing the apical elevation of the tegument (asterisk) at the anterior border of the sucker and the distribution of the seven pairs of small, rounded papillae (dotted line) that line the outer perimeter of the sucker opening $(\mathrm{Bar}=50 \mu \mathrm{m}) ; 11$ : detail of the genital pore, showing the elevated outline around most of the perimeter. Note the presence of anterior extremity of the cirrus (CI), spermatozoids (S) and tegumentary spines (arrowhead) $(\mathrm{Bar}=20 \mu \mathrm{m}) ; 12$ : detail of the ventral sucker outlined by four pairs of papillae (arrows) distributed around the perimeter of the opening, interspersed with a large number of spines (arrowhead) (Bar $=20 \mu \mathrm{m})$; 13: detail of the terminal excretory pore showing its spherical aperture, lack of spines or papillae and the presence pleats of varied size (arrows) (Bar $=20 \mu \mathrm{m})$. dae, based on the type of host and infestation pattern, as well as the morphological differences in comparison with the species of the families Mesocoeliidae, Brachycoeliidae and Dicrocoeliidae (position of the ovary relative to that of the testes, position of the genital pore and the size of the vitelline glands). The morphological characters of the trematode analyzed in the present study are consistent with the general characteristics of the genus Mesocoelium, as described by Pojmanska (2008).

Specific parameters not influenced by external factors have been searched to group species and were considered by some authors as testis position (Cheng 1960), tegument spines, ratio of oral sucker and ventral sucker, eggs size and uterine loops distribution (Freitas 1963), eggs size (Mettrick \& Dunkley 1968), suckers relation and egg diameter (Nasir \& Díaz 1971).

The first 28 species listed for the genus Mesocoelium, which were divided into three groups based on the location of the testis in relationship of ventral sucker. The testis could be on each side of the ventral sucker (1st group,
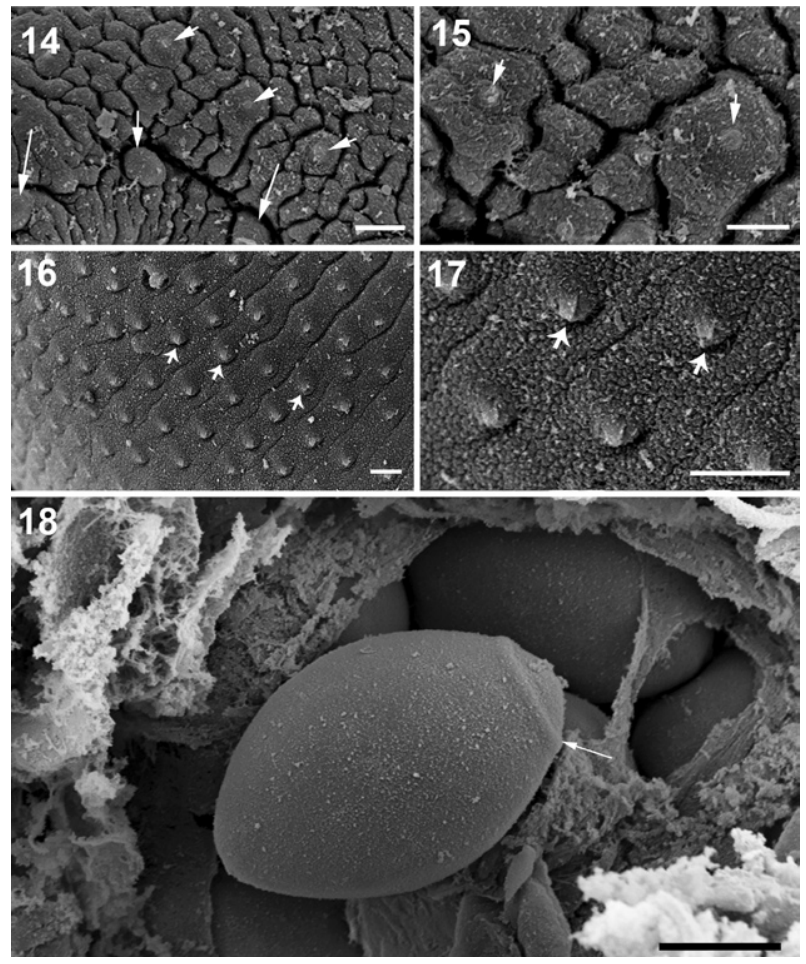

Figs 14-18: scanning electron micrographs of Mesocoelium lanfrediae sp. nov. 14: surface of the tegument of the trematode above the oral sucker, showing the randomly-distributed tegumentary papillae (arrowhead). Arrows: papillae around the opening of the oral sucker $(\operatorname{Bar}=10 \mu \mathrm{m}) ; 15$ : detail of two tegumentary papillae (arrowhead). Note the small and rounded central structure within the larger, irregular outline $(\mathrm{Bar}=5 \mu \mathrm{m}) ; 16$ : detail of the ventrolateral region of the mid-third of the body, showing numerous spines (arrowhead) $(\mathrm{Bar}=10 \mu \mathrm{m})$; 17: detail of tegumentary spines (arrowhead) showing their cuneiform shape (wide base and thin, delicate tip) $($ Bar $=10 \mu \mathrm{m})$; 18: detail of an egg showing the slightly granular surface and a small elevation (arrow) outlining the perimeter of the operculum $($ Bar $=10 \mu \mathrm{m})$. 
with 16 species), above it (2nd group comprehending 4 species) and after the ventral sucker (3rd group including 8 species) (Cheng 1960). The oblique testes position of M. lanfrediae sp. nov., situated between lateral region of the body and after the ventral sucker, difficult the allocation of this species at one of these three groups.

Freitas (1963), in Mesocoellidae review, considered only seven species for Mesocoelium. Initial parameter for differentiating these species were considered the presence of anterior digitiform tegument prolongations, that could be observed in M. crossophorum Pérez, 1942, and absent in other six species. Comparing original description by light microscopy performed by Vigueras (1942), the description, distribution and number of tegumentar projections are not similar to papillae as we described, in number, shape and distribution in M. lanfrediae sp. nov.

If we did not consider the presence of these structures and follow the classification proposed by Freitas (1963), M. lanfrediae sp. nov. could be compared with Mesocoelium monas Rudolphi 1819 and Mesocoelium brevicecum Ochi, 1929. However, these three species can be differentiated by eggs diameter (M. brevicecum $55 \mu \mathrm{m}$, M. monas $37 \mu \mathrm{m}$ and $M$. lanfrediae sp. nov. $27 \mu \mathrm{m}$ ).

Nasir and Díaz (1971) add to the character egg diameter, proposed by Mettrick and Dunkley (1968), the relation between suckers, epitomizing species of genus Mesocoelium in four: M. monas, M. brevicecum, Mesocoelium geoemydae Ozaki, 1935 and Mesocoelium megaloon Johnston, 1912. In spite of M. lanfrediae sp. nov. presents relation between suckers 1:1, similar to $M$. monas and M. brevicecum, these new species shows different values for egg diameter $(27 \mu \mathrm{m})$.

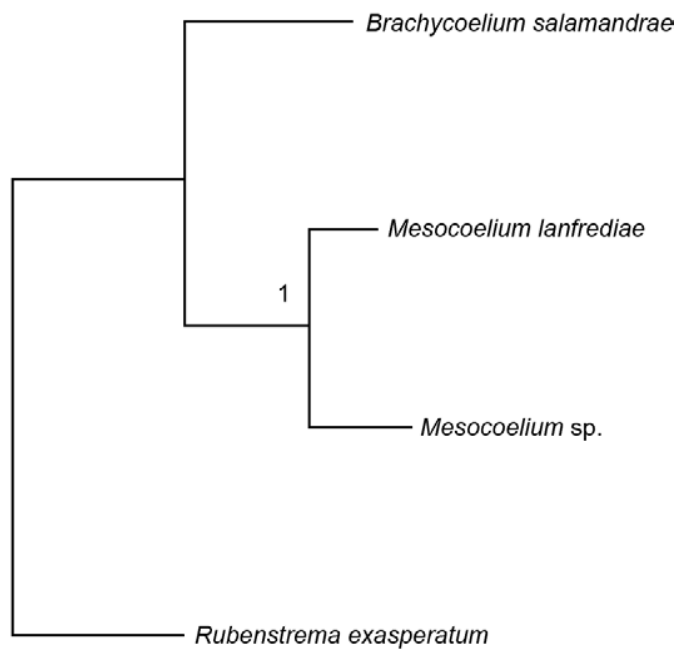

0.0030

Fig. 19: phylogenetic relationship of Mesocoelium lanfrediae sp. nov. based on Bayesian inference using Hasegawa-Kishino-Yano model, proportion of invariable sites and gamma model of DNA substitution. Bayesian posterior probability appear above node. The scale bar represents the number of substitutions per nucleotide site.

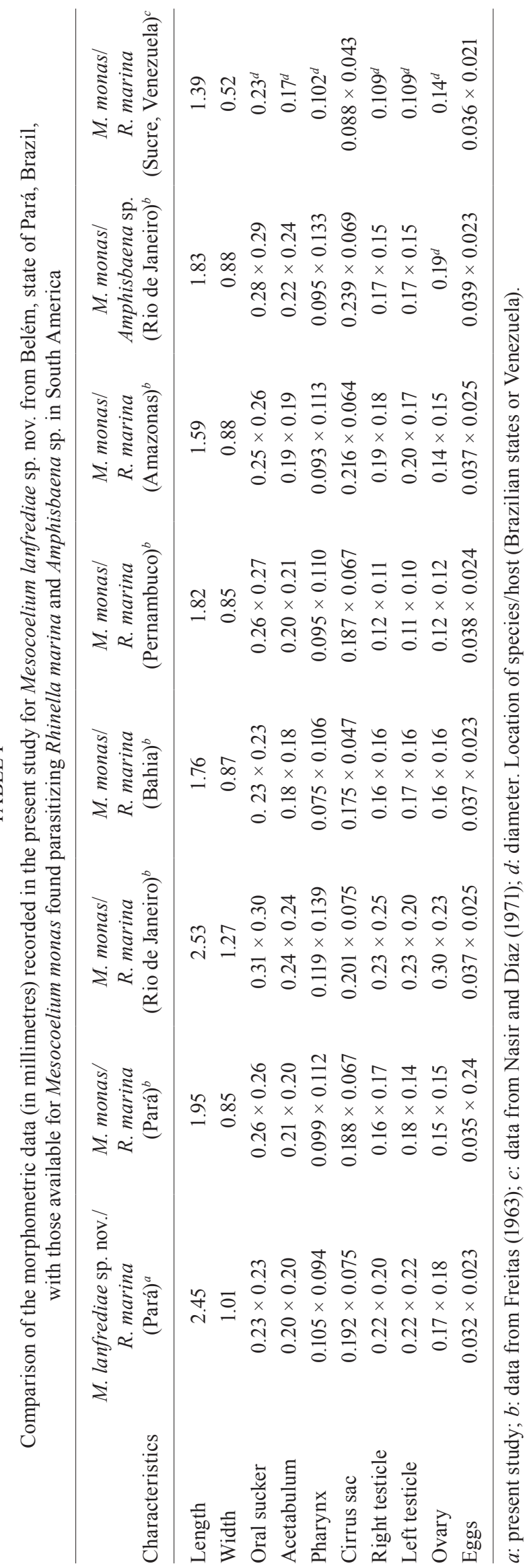


Morphological analysis induced Freitas (1963) to consider Mesocoelium sociale Lühe, 1901 (Cheng 1960) to be synonymous with $M$. monas, based on the location of the testes, after the acetabulum. Nasir and Díaz (1971) re-described $M$. monas, including new data on its morphology, as the fact that the oral sucker is larger than the ventral sucker and that both these structures have neither spines nor papillae.

$M$. lanfrediae sp. nov. shares a number of characteristics with M. monas, which also parasitizes $R$. marina. These characters include the anterior and follicular position of the vitellarium, spherical testes located after the ventral sucker, rounded ovary found just under the testes and a Y-shaped excretory vesicle.

However, M. lanfrediae sp. nov. is differentiated from all species listed and M. monas by its larger length and width and the presence of regularly-spaced papillae around the oral and ventral sucker, as well as the number of spines in ventral sucker.

A comparison of the morphometric data with those available for Mesocoelium species from South America, especially Brazil (Table) reveals a number of systematic differences. In comparison with M. monas, the new species is generally longer and wider and also has a larger pharynx, cirrus sac, testes and ovaries. Only the specimens of M. monas collected from amphibians in Rio de Janeiro, Brazil, presented measurements similar to those of $M$. lanfrediae sp. nov., but the presence of papillae in sucker and tegument has not been recorded in any other Mesocoelium species.

The molecular data presented in this study are consistent with those of Olson et al. (2003). The sequence obtained from $M$. lanfrediae sp. nov. grouped with a sequence of Mesocoelium sp., confirming the identification of genus by morphological analysis. M. lanfrediae sp. nov. presents small, spherical papillae around the external perimeter of the oral sucker and others interspersed with the spines found around the acetabulum. These features are best observed through SEM, an approach not used previously in studies of the trematodes of this genus.

Another important feature of the new species is the presence of small, rounded papillae in the tegument, that are morphologically distinct from those observed around the suckers. None of these aspects have been reported previously in mesocoelid species, so the papillae of the suckers and the tegument are described here for the first time in the genus Mesocoelium.

The SEM data represent an important advance for the analysis of the systematics of the Mesocoeliidae, by identifying new morphologic characteristics, the observations reported in the present study, including phylogenetic relationship based on SSU rDNA gene, the presence of papillae and the morphological and morphometric aspects of the trematode parasite found in the small intestine of $R$. marina unequivocally in the genus Mesocoelium, but clearly in a new species, $M$. lanfrediae sp. nov.

\section{ACKNOWLEDGEMENTS}

To Dr Reinalda Marisa Lanfredi (in memoriam), Dr Débora Henrique Anjos (UFRJ) and Dr Arnaldo Maldonado Junior (FIOCRUZ/RJ), for her helpful discussion of the results, and to Dr Wanderley de Souza, director of the Hertha Meyer Cellular Ultrastructure Laboratory (UFRJ), for the use of the scanning electron microscope.

\section{REFERENCES}

Barton DP 1997. Introduced animals and their parasites: the cane toad Bufo marinus, in Australia. Aust J Eco 22: 316-324.

Cheng TC 1960. Studies on the Trematode family Brachycoeliidae. IV. A revision of the genus Mesocoelium Odhner, 1911: and the status of Pintnaria Poche, 1907. Am Mid Nat 63: 439-469.

Dollfus RPH 1933. Répertoire dês espèses et dês genres nouveaux. Annals Parasit Hum Comp 11: 322-324.

Espinoza-Jiménez A, Garcia-Prieto L, Osorio-Sarabia D, León-Règagnon V 2007. Checklist of helminth parasites of the cane toad Bufo marinus (Anura: Bufonidae) from Mexico. J Parasitol 93: 937-944.

Freitas JFT 1963. Revisão da família Mesocoeliidae Dollfus, 1933 (Trematoda). Mem Inst Oswaldo Cruz 61: 177-312.

Hall TA 2007. BioEdit v7.0.9: Biological sequence alignment editor analysis program for Windows 95/98/Nt. [Accessed 05 Dec 2011]. Available from: mbio.ncsu.edu/BioEdit/bioedit.html.

Mettrick DF, Dunkley DF 1968. Observations on the occurrence, growth and morphological variations of the trematode, Mesocoelium danforthi Hoffman, 1935 in Jam. Caribb J Sc 8: 71-94.

Nasir P, Díaz MP 1971. A redescription of Mesocoelium monas (Rudolphi, 1819) Freitas, 1958 and specific determination in genus Mesocoelium Odhner 1910 (Trematoda: Digenea). Rev Parassitol 32: 149-158.

Olson PD, Caira JN 1999. Evolution of the major lineages of tapeworms (Platyhelminthes: Cestoidea) inferred from 18S ribosomal DNA and elongation factor-1a. J Parasitol 85: 1134-1159.

Olson PD, Cribb TH, Tkach VV, Bray RA, Littlewood DTJ 2003. Phylogeny and classification of the Digenea (Platyhelminthes: Trematoda). Int J Parasitol 33: 733-755.

Pojmanska T 2008. Family Mesocoeliidae Dollfus, 1929. In RA Bray, DI Gibson, A Jones (eds.), Keys to the Trematoda, Vol. 3, CABI Publishing/Natural History Museum, Wallingford, p. 261-263.

Posada D 2008. Modeltest: phylogenetic model averaging. Mol Biol Evol 25: 1253-1256.

Ragoo RM, Omah-Maharaj IR 2003. Helminths of the cane toad Bufo marinus from Trinidad, West Indies. Caribb J Sc 39: 242-245.

Rambaut A, Drummond AJ 2008. Tracer v1.4.1. [Accessed 10 May 2010]. Available from: tree.bio.ed.ac.uk/software/tracer.

Ronquist F, Huelsenbeck JP 2003. MRBAYES 3: Bayesian phylogenetic inference under mixed models. Bioinformatics 19: 1572-1574.

Schwarz G 1978. Estimating the dimension of a model. An Stat 6: 461-464.

Vallinoto M, Sequeira F, Sodré D, Bernardi JAR, Sampaio I, Schneider H 2010. Phylogeny and biogeography of the Rhinella marina species complex (Amphibia: Bufonidae) revisited: implications for neotropical diversification hypotheses. Zool Scripta 39: 128-140.

Vigueras IP 1942. Notas helmintologicas. Rev Univ Habana 40/42: 193-223 